\title{
Absence of neurological abnormalities in mice homozygous for the Polr3a G672E hypomyelinating leukodystrophy mutation

Karine Choquet ${ }^{1,2,3}$, Sharon Yang ${ }^{1}$, Robyn D. Moir ${ }^{4}$, Diane Forget ${ }^{5}$, Roxanne Larivière ${ }^{1}$, Annie Bouchard ${ }^{5}$, Christian Poitras $^{5}$, Nicolas Sgarioto ${ }^{1}$, Marie-Josée Dicaire ${ }^{1}$, Forough Noohi ${ }^{1,2}$, Timothy E. Kennedy ${ }^{1}$, Joseph Rochford ${ }^{6}$, Geneviève Bernard ${ }^{7,8,9}$, Martin Teichmann ${ }^{10}$, Benoit Coulombe ${ }^{5,11}$, lan M. Willis ${ }^{4}$, Claudia L. Kleinman ${ }^{2,3}$ and Bernard Brais ${ }^{1,2^{*}}$

\begin{abstract}
Recessive mutations in the ubiquitously expressed POLR3A gene cause one of the most frequent forms of childhood-onset hypomyelinating leukodystrophy (HLD): POLR3-HLD. POLR3A encodes the largest subunit of RNA Polymerase III (Pol III), which is responsible for the transcription of transfer RNAs (tRNAs) and a large array of other small non-coding RNAs. In order to study the central nervous system pathophysiology of the disease, we introduced the French Canadian founder Polr3a mutation c.2015G > A (p.G672E) in mice, generating homozygous knock-in $(\mathrm{Kl} / \mathrm{KI})$ as well as compound heterozygous mice for one Polr3a $\mathrm{Kl}$ and one null allele (KI/KO). Both $\mathrm{Kl} / \mathrm{Kl}$ and $\mathrm{KI} / \mathrm{KO}$ mice are viable and are able to reproduce. To establish if they manifest a motor phenotype, $\mathrm{WT}, \mathrm{KI} / \mathrm{Kl}$ and $\mathrm{KI}$ / $\mathrm{KO}$ mice were submitted to a battery of behavioral tests over one year. The $\mathrm{KI} / \mathrm{KI}$ and $\mathrm{KI} / \mathrm{KO}$ mice have overall normal balance, muscle strength and general locomotion. Cerebral and cerebellar Luxol Fast Blue staining and measurement of levels of myelin proteins showed no significant differences between the three groups, suggesting that myelination is not overtly impaired in Polr3a KI/KI and KI/KO mice. Finally, expression levels of several Pol III transcripts in the brain showed no statistically significant differences. We conclude that the first transgenic mice with a leukodystrophy-causing Polr3a mutation do not recapitulate the childhood-onset HLD observed in the majority of human patients with POLR3A mutations, and provide essential information to guide selection of Polr3a mutations for developing future mouse models of the disease.
\end{abstract}

Keywords: Leukodystrophy, POLR3A, Mouse model, Hypomyelination, RNA Polymerase III, Transfer RNAs

\section{Background}

Hypomyelinating leukodystrophies are a heterogeneous group of neurodegenerative diseases characterized by impaired cerebral myelin formation. POLR3-related hypomyelinating leukodystrophy (POLR3-HLD), also called $4 \mathrm{H}$ leukodystrophy, is caused by recessive mutations in POLR3A, POLR3B or POLR1C [1-4]. Patients usually present in early childhood or adolescence with motor regression, cerebellar features and/or cognitive

\footnotetext{
* Correspondence: bernard.brais@mcgill.ca

'Montreal Neurological Institute, McGill University, 3801 University Street, room 622, Montréal, Québec H3A 2B4, Canada

2Department of Human Genetics, McGill University, Montréal, Québec, Canada

Full list of author information is available at the end of the article
}

dysfunction $[1,5]$. In many cases, they also display hypogonadotropic hypogonadism and/or hypodontia $[1,5]$. Diffuse hypomyelination with relative preservation (T2 hypointensity) of myelination of the dentate nuclei, anterolateral nuclei of the thalami, globi pallidi and optic radiations, as well as a thin corpus callosum and cerebellar atrophy are observed on magnetic resonance imaging (MRI) in the majority of POLR3-mutated patients [5-8].

POLR3A, POLR3B and POLR1C encode subunits of RNA Polymerase III (Pol III), one of the three essential eukaryotic RNA polymerases. Specifically, Pol III is responsible for the synthesis of several types of noncoding RNAs (ncRNAs), including transfer RNAs (tRNAs), 5S ribosomal RNA (rRNA), U6 small nuclear RNA and BC200 RNA [9]. Pol III is a large enzymatic 
complex composed of 17 subunits. POLR3A and POLR3B, the two largest subunits, form the catalytic center of the enzyme.

Since the initial identification of mutations in POLR3A [1], more than 100 mutations in POLR3A, POLR3B and POLR1C have been identified in over 130 patients with POLR3-HLD [1-5, 8, 10-19]. The majority of mutations are private or present in only a handful of patients [5]. While most international POLR3-HLD patients are compound heterozygotes, the majority of French Canadian cases are homozygous for the c.2015G > A (p.G672E) mutation in POLR3A, suggesting a founder effect in this population $[1,5]$. In addition to this genetic heterogeneity, POLR3-HLD is characterized by important interand rarely intra-familial clinical variability, both in symptoms and severity, and its phenotypic spectrum continues to expand $[8,20,21]$. Notably, two recent studies described patients with cerebellar atrophy only [8] or with involvement of the striatum and red nuclei but normally myelinated white matter [21], suggesting that diffuse hypomyelination is not an obligate feature of the disorder [8].

Despite the major advances in the clinical and genetic characterization of POLR3-HLD, the molecular basis of its pathophysiology remains poorly understood. Mutations are located throughout the three genes and are likely to impact different functional aspects of Pol III, which would in all cases lead to enzyme hypofunction and decreased expression of ncRNAs synthesized by Pol III $[1-3,22]$. Indeed, a recent study using FLAG-tagged POLR1C mutants transfected in HeLa cells demonstrated that two POLR1C missense mutations cause impaired assembly of the Pol III complex, accumulation of the mutated subunits in the cytoplasm and reduced Pol III occupancy at its target promoters, suggesting decreased transcription of the corresponding genes [3]. In addition, overexpression of missense alleles of $R p c 1$, the yeast ortholog of POLR3A, in S. pombe, led to reduced precursor tRNA levels, a proxy for transcription, and changes in tRNA modification and translation fidelity [23]. A key question is how mutations in such an essential and ubiquitously expressed enzymatic complex lead to a central nervous system (CNS)-specific disease. Most Pol III transcripts are ubiquitously expressed and several of them are at their highest expression level in the CNS [24, 25]. Moreover, POLR3-HLD belongs to a growing number of neurological diseases, including several leukodystrophies, caused by mutations in genes that are also related to tRNA biology [26-32], suggesting that impaired tRNA biogenesis could be particularly detrimental to the CNS.

In this study, we generated and characterized a knockin (KI) mouse model carrying the common French Canadian Polr3a c.2015G > A (p.G672E) mutation in order to determine if it recapitulates POLR3-HLD features. Herein, we describe the results from a yearlong study of motor function in this first transgenic exploratory model of POLR3-HLD, as well as its molecular and histological characterization.

\section{Results}

\section{Generation of Polr3a KI/KI and KI/KO mouse models}

To obtain a relevant model of POLR3-HLD, we generated a KI mouse carrying the c.2015G > A (p.G672E) mutation in Polr3a, a mutation chosen based on its frequency in French Canadian cases and on the report of several human homozygous cases $[1,5]$. Indeed, we obtained viable $\mathrm{KI} / \mathrm{KI}$ mice and confirmed the expression of the homozygous c.2015G > A (p.G672E) mutation in these animals by Sanger sequencing of tail genomic DNA as well as brain cDNA (Additional file 1: Figure S1A). We also generated a compound heterozygous Polr3a mouse line carrying one KI allele and one null allele (KI/KO). Heterozygous Polr3a knockout (KO) mice were produced by insertion of a gene trap cassette in intron 21. The portion of intron 21 upstream of the cassette is retained in the mRNA of these mice, leading to a frameshift and premature stop codon (p.E968VfsX12) (Additional file 1: Figure S2). As expected, homozygous Polr3a KO mice are embryonically lethal (Additional file 1: Figure S1B). KI/KI mice were bred with heterozygous Polr3a KO mice to create the $\mathrm{KI} / \mathrm{KO}$ mouse line. Both $\mathrm{KI} / \mathrm{KI}$ and $\mathrm{KI} / \mathrm{KO}$ mice reproduce normally and do not display a grossly abnormal phenotype at 12 months of age. At the protein level, full-length POLR3A levels were comparable in the cerebrum of one-year-old $\mathrm{KI} / \mathrm{KI}, \mathrm{KI} /$ $\mathrm{KO}$ and WT mice (Additional file 1: Figure S1D). The $\mathrm{KO}$ allele is predicted to cause a frameshift leading to premature termination at amino acid 980 and resulting in a protein of approximately $100 \mathrm{kDa}$. We did not observe a band of that size accumulating in $\mathrm{KI} / \mathrm{KO}$ mice (Additional file 1: Figure S1D), implying that the KO mRNA and/or protein is rapidly degraded. In addition, the normal levels of full-length protein in $\mathrm{KI} / \mathrm{KI}$ and $\mathrm{KI} /$ $\mathrm{KO}$ mice indicate that the G672E mutation does not impair stability of the POLR3A protein.

\section{Characterization of motor function over one year}

Individuals with POLR3A mutations, including those homozygous for the c.2015G > A (p.G672E) mutation, manifest cerebellar and upper motor neuron signs leading to impaired gait, coordination and balance as well as cognitive dysfunction [1]. We thus performed balance beam, rotarod, open field and inverted grid tests to assess balance, coordination, general locomotion, and muscle strength (Fig. 1). Since the body weights of the mice were variable, especially at later time points (Additional file 1: Figure S3), we used one-way analysis of 

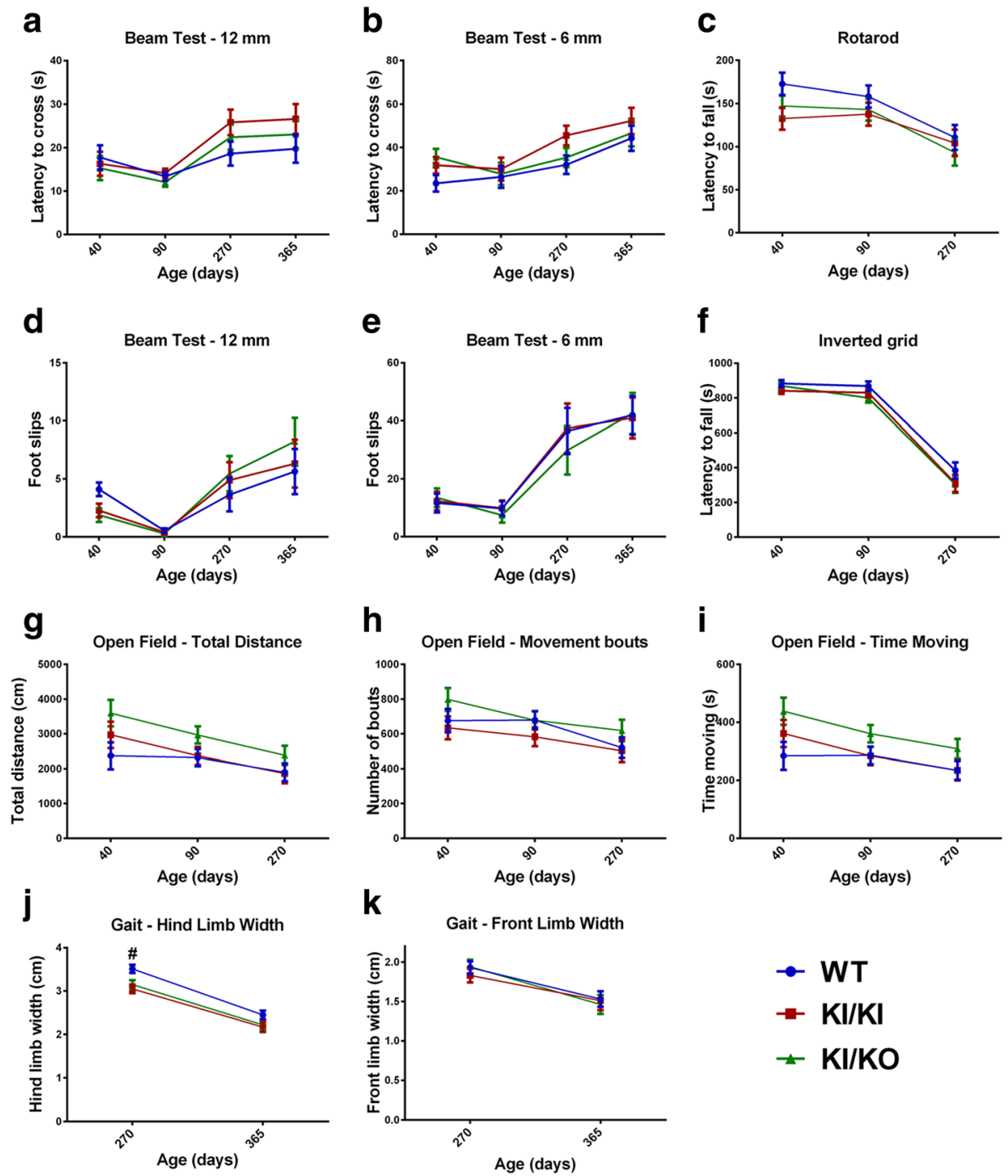

i

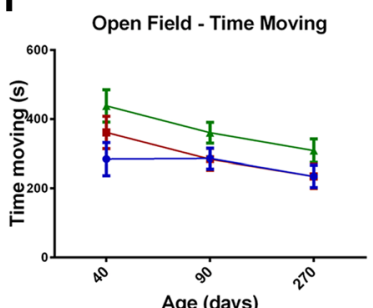

$$
\text { Age (days) }
$$

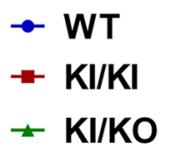

Fig. 1 Yearlong study of motor function in Polr3a KI/KI and KI/KO mice. Results from the $12 \mathrm{~mm}(\mathbf{a}, \mathbf{d})$ and $6 \mathrm{~mm}(\mathbf{b}$, e) beam test at four time points consisting of three trials per mouse. Latencies to cross $(\mathbf{a}, \mathbf{b})$ and number of foot slips $(\mathbf{d}, \mathbf{e})$ were recorded for both beam sizes. $\mathbf{c}, \mathbf{f})$ Results from the rotarod $(\mathbf{c})$ and inverted grid $(\mathbf{f})$ tests performed at three time points. The rotarod and inverted grid consisted of three trials per mouse. $\mathbf{g - i}$ ) Results from the open field test performed at three time points. The open field test was run for 90 min per mouse during which total distance traveled $(\mathbf{g})$, number of movements bouts $(\mathbf{h})$ and total time spent moving (i) were recorded for each 10 min interval. The results represent the sum of all 10 min intervals. $\mathbf{j}$-k) Results from gait analysis performed at the two latest time points. Paws were covered in color paint and mice were allowed to walk on a white paper-covered narrow runway. Distance between fore limbs and hind limbs was measured. All tests were performed on $\geq 14$ female mice per group. For the beam test, rotarod and inverted grid, data are represented as adjusted least squares means $+/-$ SEM of the sum of the three trials for each group. Groups were compared with one-way ANCOVA for each time point. \#: $p<0.01$

covariance (ANCOVA) with weight as the covariate to compare behavioral measures between genotypes (Fig. 1). At 40 and 90 days old, there were no significant differences between the three groups, implying that Polr3a KI/KI and KI/ KO mice do not develop an early-onset motor phenotype. While some differences were observed on the beam test at 270 and 365 days old (Additional file 1: Figure S4), those were largely attributable to weight and did not remain after adjustment of the data for this variable (Fig. 1). To complement the beam test, we performed gait analysis (Fig. 1j-ik).
Both $\mathrm{KI} / \mathrm{KI}$ and $\mathrm{KI} / \mathrm{KO}$ mice displayed a small but statistically significant reduction in their back paws limb width compared to WT mice ( $p$-value $<0.01)$ at 270 days old. The test was repeated at 365 days old and showed the same trend but the difference between groups was not statistically significant (Fig. 1j). This may reflect a very mild phenotype that would require testing of older mice for confirmation. In summary, the extensive panel of tests performed strongly suggests that Polr3a KI/KI and KI/KO mice do not display motor dysfunction at one year of age. 


\section{Analysis of myelination and cerebellar integrity}

Hypomyelination is the main pathological feature of POLR3-HLD [5, 33]. Thus, to assess whether Polr3a KI/ $\mathrm{KI}$ and $\mathrm{KI} / \mathrm{KO}$ mice display hypomyelination, we stained coronal brain sections from 90 and 365 days old mice with Luxol Fast Blue (LFB), which is commonly used to detect myelin in the CNS. We observed normal and complete myelination in the brain and cerebellum of $\mathrm{KI} /$ $\mathrm{KI}$ and $\mathrm{KI} / \mathrm{KO}$ mice, where the staining was indistinguishable from age-matched WT mice (Fig. 2a, b and Additional file 1: Figure S5). In addition, we measured the levels of the major protein components of myelin by western blot in the cerebellum of 90-day-old mice. Protein levels of Myelin Basic Protein (MBP), Proteolipid Protein (PLP), Myelin-associated Glycoprotein (MAG) and 2',3'-Cyclic Nucleotide 3' Phosphodiesterase (CNP) were comparable between WT, $\mathrm{KI} / \mathrm{KI}$ and $\mathrm{KI} / \mathrm{KO}$ mice (Fig. 2c). These results suggest that Polr3a KI/KI and $\mathrm{KI} / \mathrm{KO}$ mice undergo normal gross myelination and do not experience major demyelination at one year of age. Since cerebellar atrophy and Purkinje cell loss is a major feature in POLR3-HLD [5, 33], we then evaluated cerebellar morphology using Nissl staining followed by Purkinje cell counts in 365-day-old mice. Cerebellar morphology was overall normal (Fig. 3a) as were Purkinje cell numbers (Fig. 3b), implying that $\mathrm{KI} / \mathrm{KI}$ and $\mathrm{KI} /$ $\mathrm{KO}$ mice do not present cerebellar atrophy.

\section{Evaluation of Pol III transcription levels}

Despite the lack of severe abnormalities at the phenotypic and histological levels, the homozygous c.2015G > A (p.G672E) substitution in Polr3a may alter Pol III function. Because of their short half-lives, precursor tRNA levels provide a reliable estimate of Pol III transcription [34-36]. To evaluate the impact of the Polr3a G672E mutation on Pol III transcription, we measured the levels of one precursor tRNA and two mature tRNAs in the cerebrum and liver of 90-days-old and one-yearold WT, KI/KI and KI/KO mice (Fig. 4a and Additional file 1: Figure S6). While there were no statistically significant differences in tRNA levels among the three groups, there was a trend towards a small decrease of pre-tRNA $^{\text {Ile(TAT) }}$ in one-year-old KI/KO mice (Fig. 4a). We then reasoned that brain-specific transcripts, such as Bc1 RNA and n-Tr20 tRNA [37], might be more sensitive to Pol III mutations. We first confirmed the brainspecific expression of both transcripts (Additional file 1: Figure S6). We then measured the levels of Bc1 RNA, precursor $\mathrm{n}-\operatorname{Tr} 20$ as well as mature $\mathrm{n}$ - $\operatorname{Tr} 20$ in the cerebrum of WT, KI/KI and KI/KO mice, but we did not detect differences between groups (Fig. 4 and Additional file 1: Figure S6). Therefore, our results suggest that the Polr3a G672E mutation does not significantly impair Pol III transcript levels, although it may result in a minor effect on the transcription of tRNA genes in whole cerebrum of one-year-old Polr $3 a \mathrm{KI} / \mathrm{KO}$ hypomorphic mice.

\section{Impact of the POLR3A G672E mutation in human cells}

Because of the absence of dysfunction resulting from the c.2015G > A (p.G672E) mutation in mouse, we sought to evaluate its impact on Pol III function in human cells. We stably expressed FLAG-tagged versions of WT and mutant (G672E) POLR3A in HeLa cells. We first examined the impact of the G672E mutation on POLR3A cellular localization by performing anti-FLAG immunofluorescence. As expected, POLR3A-WT showed a predominant nuclear localization. Similarly, the majority of POLR3AG672E was also in the nucleus, albeit with slightly more of the protein in the cytoplasm compared to WT. This suggests that the mutant Pol III complex is generally correctly assembled and imported into the nucleus (Fig. 5a). To further confirm this, we performed anti-FLAG affinity

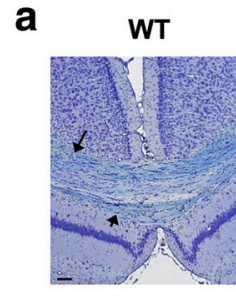

b

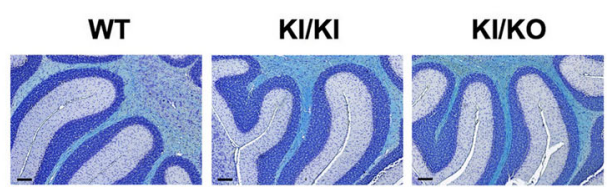

c

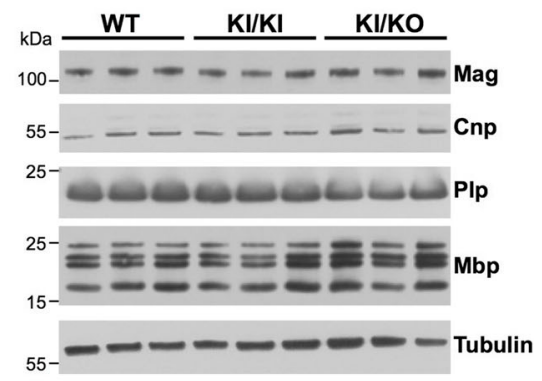

Fig. 2 Normal myelination in Polr3a KI/KI and KI/KO mice. a-b) Luxol Fast Blue staining of coronal sections (a) showing the corpus callosum (long arrow) and dorsal fornix (short arrow), both myelinated, and of sagittal sections (b) of the cerebellum. Staining was performed on three 90 days old mice per group and representative images are shown for each group. Scale bar $=100 \mu \mathrm{m}$. c) Immunoblots of myelin proteins using total protein extracts from the brain of 90 days old $\mathrm{WT}, \mathrm{KI} / \mathrm{KI}$ and $\mathrm{KI} / \mathrm{KO}$ mice 

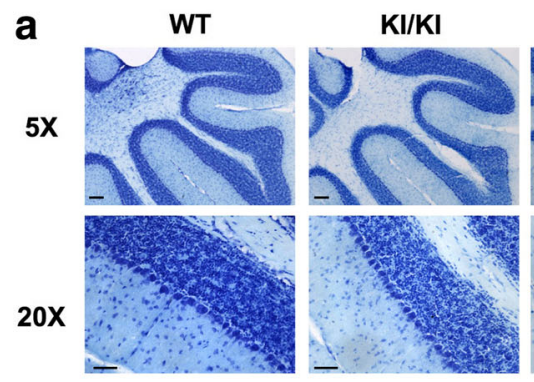

$\mathrm{KI} / \mathrm{KO}$

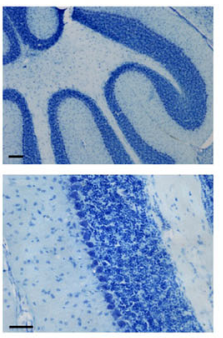

b

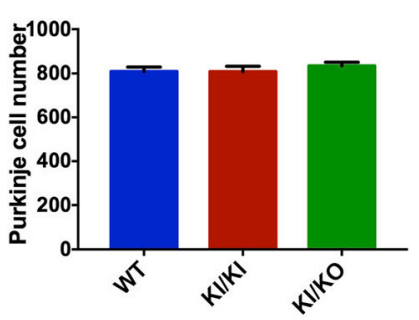

Fig. 3 No Purkinje cell loss in Polr3a Kl/KI and Kl/KO mice. a) Nissl staining of sagittal cerebellar sections of 365 days old mice. Staining was performed on four mice per group and representative image are shown for each group. Scale bar $=100 \mu \mathrm{m}$ (top) and $50 \mu \mathrm{m}$ (bottom). b) Purkinje cell counts of mid-sagittal cerebellar sections of 365 days old mice ( $n=4$ per group). Data are represented as mean $+/-$ SEM
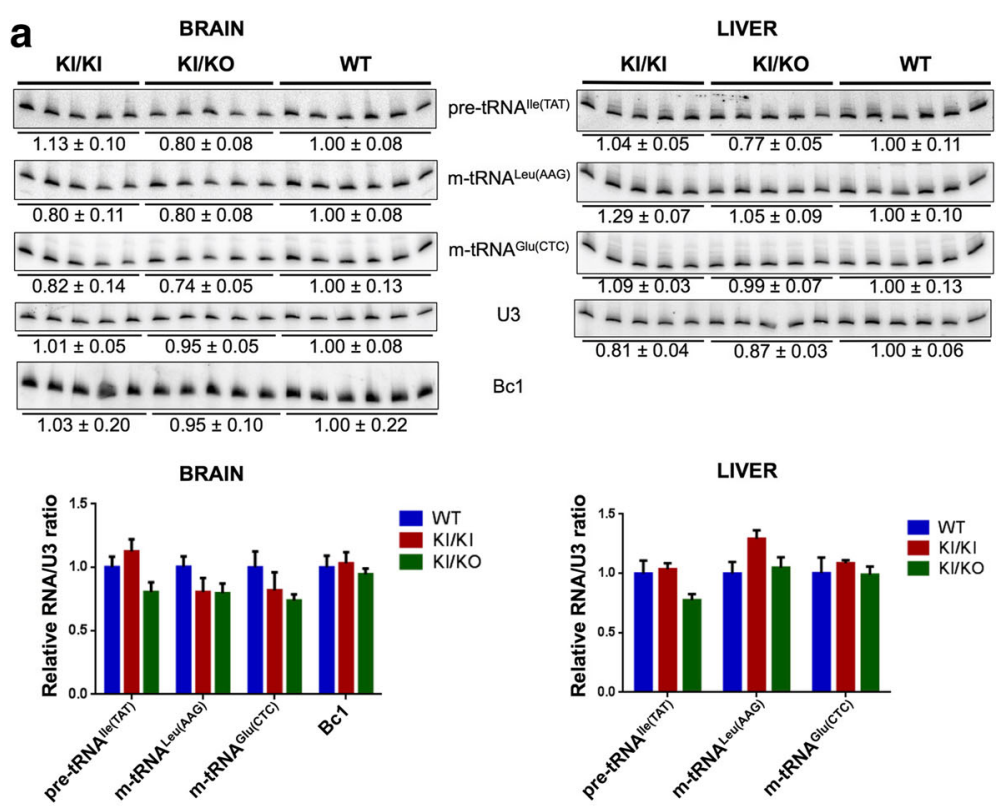

Bc1
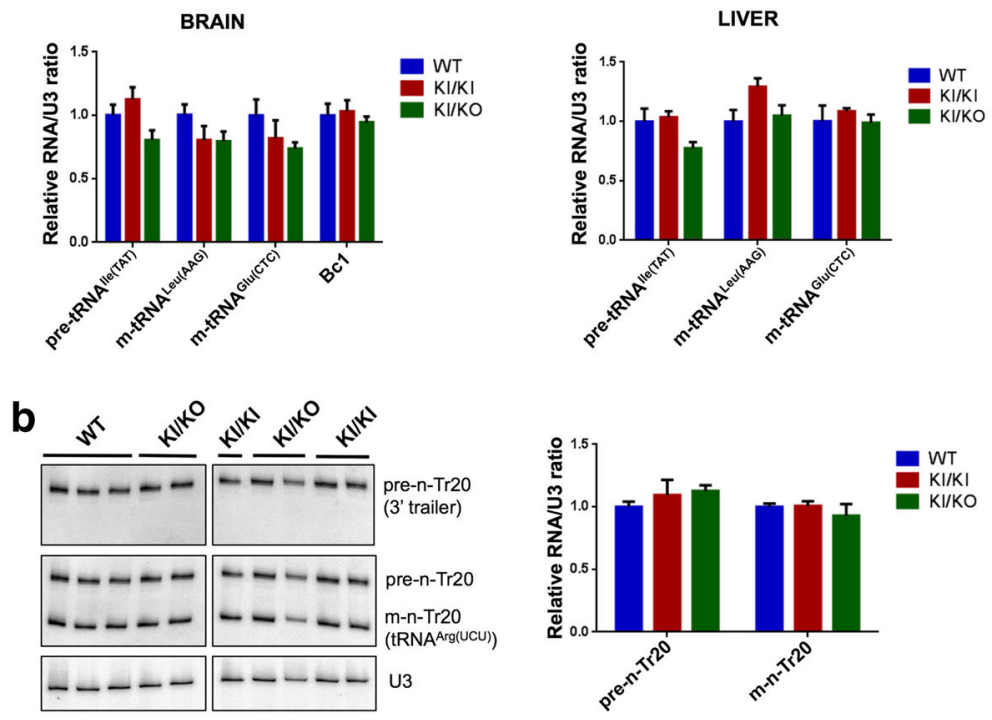

Fig. 4 Expression levels of Pol III transcripts in the cerebrum and liver of Polr3a KI/KI and KI/KO mice. a) Top: Northern blots of precursor (pre) and mature (m) tRNA species from the cerebrum (left) and liver (right) of 365 days old mice. U3 snRNA was used as a loading control. Bc1 RNA was probed in the cerebrum only. Mean +/- SEM of tRNA or BC1 levels normalized to U3 snRNA levels are indicated below the blot for each transcript. Bottom: Quantification of Pol III transcripts surveyed by Northern Blot. tRNA levels were normalized to U3 snRNA levels. Data are represented as mean +/- SEM. b) Left: Northern blot of precursor (pre) and mature (m) n-Tr20 tRNA Arg(UCU) in the cerebrum of 3-months-old mice, demonstrating low levels of $n$-Tr20, consistent with these mice having the C57BL/6 J n-Tr20 genotype (see also Additional file 1: Figure S6B). Right: Quantification of precursor and mature n-Tr20 levels, normalized to U3 snRNA levels 


\section{a}

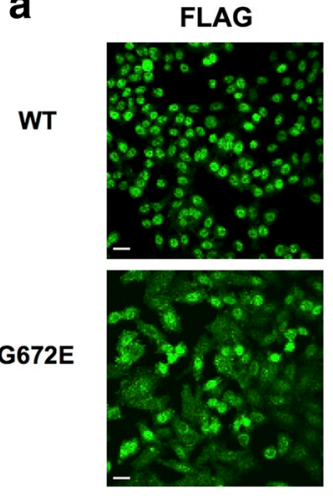

C

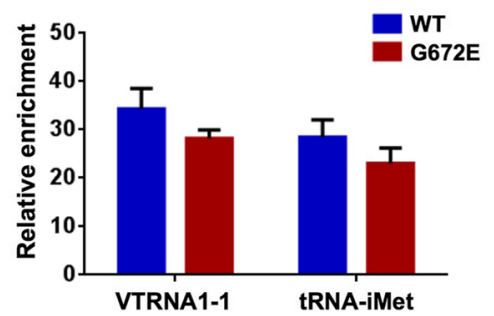

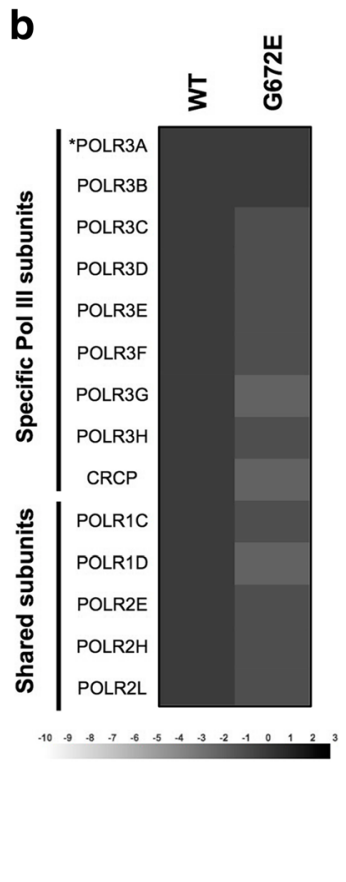

Fig. 5 Impact of POLR3A G672E mutation on Pol III function in human cells. a) Immonufluorescence experiment showing the predominant nuclear localization of FLAG-tagged variants of POLR3A (WT or G672E). Scale bar $=20 \mu \mathrm{m}$. b) FLAG-tagged variants of POLR3A (WT or G672E) were expressed at equivalent levels in HeLa cells and purified using anti-FLAG affinity chromatography. The co-purified proteins were identified by LCMS/MS. The heatmap contains the $\log _{2}$-transformed average spectral count ratios of G672E/WT across both replicates. Spectral counts were computed with Mascot. Specific and shared (with Pol I and/or Pol II) subunits are identified on the left. POLR3A (the bait) is identified by an asterisk. c) ChIP-qPCR performed against FLAG-tagged variants POLR3A-WT and POLR3A-G672E expressed transiently at equivalent levels in HEK293 cells. The chromatin was quantified by qPCR with primers for two Pol III target gene promoters (VTRNA1-1 and tRNA-iMet). Pol III enrichment at these loci was calculated relative to a locus on chromosome 13 that is not bound by Pol III. Data are represented as mean +/SEM of biological triplicates

purification on cell extracts from cell lines expressing FLAG-tagged POLR3A-WT and POLR3A-G672E and analyzed the purified proteins using shotgun proteomics. The mutant POLR3A-G672E subunit was able to pull down all detectable Pol III subunits with levels that did not significantly differ from the WT subunit, indicating that the Pol III complex assembles correctly and thus that the mutation does not globally impair Pol III complex assembly (Fig. 5b, Additional file 1: Table S1). Finally, we performed chromatin immunoprecipitation followed by quantitative PCR (ChIP-qPCR) to evaluate Pol III occupancy at two target loci after transient transfection of POLR3A-WT or POLR3A-G672E in HEK293 cells. This showed a mild reduction in Pol III occupancy for POLR3A-G672E compared to POLR3A-WT, but the difference was not statistically significant (Fig. 5c). These results suggest that the impact of the POLR3A c.2015G > A (p.G672E) mutation on Pol III function is also mild in human cultured cells.

\section{Discussion}

In this study, we describe the first transgenic mice with bi-allelic mutations in Polr3a, encoding the largest subunit of Pol III. We report that these mice do not display gross hypomyelination or cerebellar atrophy. In fact, our data shows apparently normal myelin staining and myelin protein levels in $\mathrm{KI} / \mathrm{KI}$ and $\mathrm{KI} / \mathrm{KO}$ mice at 90 days of age, thereby excluding the presence of hypomyelination in these mice. Furthermore, we did not find evidence of demyelination, gross cerebellar atrophy or Purkinje cell loss in the brains of mice at one year of age. This is consistent with the absence of statistically significant motor dysfunction in one-year-old Polr $3 a \mathrm{KI} /$ $\mathrm{KI}$ and $\mathrm{KI} / \mathrm{KO}$ mice. Altogether, our results are in stark contrast with the observations in the majority of human patients affected with POLR3-HLD described to date, who manifest diffuse hypomyelination and cerebellar atrophy on MRI, childhood-onset ataxia often leading to loss of gait and speech, and death in adolescence or early adulthood [5].

This first report of a missense mutation in subunits of Pol III in a vertebrate model organism thus demonstrates that bi-allelic mutations in Polr3a do not necessarily lead to leukodystrophy and/or cerebellar dysfunction in mice, and that Pol III vulnerability to mutations may vary between species. Indeed, a previous 
report showed that a splice site substitution in zebrafish polr $3 \mathrm{~b}$, leading to an in-frame deletion of 41 amino acids, resulted in impaired intestinal and exocrine pancreas development in the larvae, with no CNS or myelination defects reported [38]. Importantly, instead of the expected $50 \%$ decrease in POLR3A protein level in $\mathrm{KI} /$ $\mathrm{KO}$ mice, we observed normal levels of the full-length protein. This may be due to a compensation mechanism that allows overcoming the loss of one allele by maintaining normal levels of full-length protein, but further experiments are warranted to establish whether this is true. Of note, in one deceased POLR3-HLD patient carrying a heterozygous nonsense mutation in POLR3A, there were only $26.8 \%$ and $6.8 \%$ decreases in POLR3A protein levels in the white matter and the cortex, respectively, compared to a healthy control [1]. This is in agreement with our observation that a heterozygous premature stop codon in POLR3A does not necessarily lead to a $50 \%$ loss of full-length protein. Furthermore, this may account for the fact that the $\mathrm{KI} / \mathrm{KO}$ mice are not more severely affected than KI/KI mice, but does not explain the lack of myelin-related phenotype in G672E mutant mice. At the molecular level, we show that the levels of five Pol III transcripts are largely unaffected in the cerebrum and liver of Polr3a KI/KI and $\mathrm{KI} / \mathrm{KO}$ mice, although there was a trend towards a small decrease in precursor tRNA-Ile levels in oneyear-old $\mathrm{KI} / \mathrm{KO}$ mice. While this is consistent with the absence of a clinical or histological phenotype, it surprisingly implies that certain Pol III mutants can function well enough to maintain overall normal levels of Pol III transcripts and general homeostasis in mice. Of note, we cannot exclude effects on the expression of other Pol III targets, especially since Pol III-transcribed genes vary in their promoter structure and associated transcription machinery [39]. Recently, the Pol III transcriptome was investigated in the blood of patients with a homozygous POLR3A splice site mutation. This mutation produces an aberrant POLR3A mRNA, which is reduced in abundance by $37 \%$ relative to the wild-type mRNA [21]. In addition to the technical limitations of assessing tRNA levels in a heterogeneous cell population such as blood, the results suggest that there is only a modest defect in Pol III function in these patients, with 7/46 tRNA isoacceptors showing statistically significant changes. Furthermore, the study reports an increase in the levels of 5S rRNA, RMRP and RPPH1 in patients [21], which is difficult to reconcile with a reduced level of functional POLR3A protein. Investigation of Pol III transcript levels in skin fibroblasts of a classical POLR3-HLD case did not uncover differences in 7SL RNA levels between the patient and a control [14], but this could be due to the fact that fibroblasts, just as blood, are not affected in the disease. Levels of Pol III transcripts were not analyzed in the brain of two deceased POLR3-HLD patients [5, 33].

To better understand the phenotypic discrepancy between human POLR3-HLD cases and our mutant mice, we analyzed the impact of the POLR3A G672E mutation on Pol III function in human cells, as was previously done for leukodystrophy-causing POLR1C mutations [3]. Our results suggest that the effect of the POLR3A G672E mutation is milder than the aforementioned POLR1C mutations. In fact, we show that the Pol III complex containing the FLAG-tagged POLR3A-G672E is properly assembled and has a predominant nuclear localization. This is in contrast to the severe complex assembly defect and cytoplasmic localization of both reported POLR1C mutants [3]. Although we observed a mild reduction in Pol III occupancy on chromatin for POLR3A-G672E, this was much more pronounced for the POLR1C mutants. Some of the difference may be explained by the different techniques used (ChIP-qPCR vs. ChIP-Seq, transient vs. stable transfections) [3]. Thus, we cannot exclude that a more substantial defect in Pol III occupancy could be uncovered for POLR3A-G672E using genome-wide techniques. Furthermore, it is possible that the G672E mutation impairs downstream processes such as transcriptional elongation or termination, but this could not be evaluated in the transfected cells since they still express the endogenous POLR3A. The mild impact of the G672E mutation in human cells perhaps explains why this mutation is viable in the homozygous state in humans, and appears to be in agreement with the milder phenotype observed in a subset of patients with this mutation [1].

The human and mouse POLR3A proteins share 97.99\% sequence identity and the region surrounding the G672E mutated site (20 amino acids on each side) is perfectly conserved (multiple protein alignment by Clustal Omega [40]). The lack of a strong phenotype in Polr3a KI/KI and KI/KO mice could potentially be explained by the much higher proportion of white matter in the human brain (more than 50\%) compared to other species (around 10\% in mouse) [41-43]. This might make the human brain more vulnerable than the mouse brain to mutations in genes important for myelination. Furthermore, oligodendrogliogenesis is thought to occur at a different pace in humans and mice, perhaps leading to differences in susceptibility to myelin abnormalities [44]. In fact, the disruption of genes causing leukodystrophies in humans does not always produce the same phenotype in mouse. Mouse models have been published for a number of leukodystrophies, but in several of them, the CNS myelin defects are milder than in humans or even completely absent. For example, null mice for $C x 47$ or homozygous $C x 47^{M 282 T / M 282 T}$ mice show only mild 
myelin deficits, contrary to human patients with mutations in its human ortholog, GJC2, which causes Pelizaeus-Merzbacher-like disease [43, 45]. Inactivation of $A b c d 1$ in mice, associated with human adrenoleukodystrophy (ALD), leads to a late-onset neurological phenotype that resembles adrenomyeloneuropathy, with abnormal myelin and axonal loss in the spinal cord and the sciatic nerve, but these mice do not display the cerebral demyelination characteristic of cerebral ALD [46].

Another possible explanation for the absence of a phenotype in mice is the existence of primate-specific Pol III transcripts. The best example is BC200 RNA, a brain-specific Pol III transcript that is thought to regulate subcellular translation in dendrites [47]. BC200 is only present in primates. Although there is a functional analog (Bc1) in mouse, $\mathrm{Bc} 1$ and $\mathrm{BC} 200$ have different evolutionary origins [48]. While we did not observe differences in $\mathrm{Bc} 1$ levels in $\mathrm{KI} / \mathrm{KI}$ and $\mathrm{KI} / \mathrm{KO}$ mice, we cannot exclude the possibility that $\mathrm{BC} 200$ may be sensitive to Pol III mutations and have a unique function in the human $\mathrm{CNS}$ that is not recapitulated by $\mathrm{Bc} 1$ in the mouse. In this scenario, the brain-specific expression of BC200 could explain the mainly CNS manifestations of POLR3-HLD. In recent years, several novel Pol III transcriptional units have been discovered in the human genome. Some of these transcripts are specifically expressed in neuronal cell lines where they have been found to regulate alternative splicing, proliferation, differentiation or cell cycle progression [49-54]. Although functional homologs have been identified in the mouse genome for some of these transcripts, they are not orthologous to their human counterparts. Deregulation of such transcripts could be responsible for the phenotype in humans, but their absence or different evolutionary origin in rodents would not lead to the same manifestations in mice.

The phenotypic spectrum of POLR3-HLD in humans is wide, regarding severity, age of onset and nature of symptoms [5]. Among individuals homozygous for the c.2015G > A (p.G672E) mutation, the disease severity is highly variable, even within families, with $2 / 5$ cases still ambulatory in early adulthood (unpublished data). One possibility is that Polr3a $\mathrm{KI} / \mathrm{KI}$ and $\mathrm{KI} / \mathrm{KO}$ mice, which carry the same c.2015G > A (p.G672E) mutation, more closely resemble these milder cases. On the other hand, these patients still displayed hypomyelination on MRI [1], while our histology data shows normal myelination in our mice. A recent study described patients with mutations in POLR3A or POLR3B without hypomyelination, suggesting that this feature is not obligate for POLR3related disorders [8]. However, cerebellar atrophy and corresponding clinical symptoms were evident in these individuals [8], contrary to the observations in Polr3a $\mathrm{KI} / \mathrm{KI}$ and $\mathrm{KI} / \mathrm{KO}$ mice. Nonetheless, it is important to note that our experiments were aimed at detecting major differences in the transgenic mice compared to WT mice. The LFB and Nissl stains and immunoblots we performed do not exclude the possibility of altered myelin ultrastructure or physiological dysfunction of Purkinje cell neurons $[55,56]$. It remains possible that $\mathrm{KI} / \mathrm{KI}$ and $\mathrm{KI} / \mathrm{KO}$ mice will develop later-onset phenotypic abnormalities due to mild pathological mechanisms, but uncovering these events is beyond the scope of the present study, which focused on establishing whether $\mathrm{KI} / \mathrm{KI}$ and $\mathrm{KI} / \mathrm{KO}$ mice represent a good model for childhood-onset POLR3-HLD. Nevertheless, the important phenotypic heterogeneity observed in POLR3HLD suggests the existence of additional genetic or epigenetic factors that can modify the presentation of the disease. The presence of certain genetic variants may be necessary in order to develop a severe form of the disease. If this is the case, introducing the Polr3a KI mutation in different mouse backgrounds could lead to a neurological phenotype. Mouse genetic backgrounds often influence the severity of a gene $\mathrm{KO}$ or $\mathrm{KI}[57,58]$, and comparison of the same mutation in different strains could allow identification of genetic modifiers [59]. Environmental stressors could also accentuate the disease presentation. This is the case in Vanishing White Matter (VWM) disease, which is caused by mutations in genes encoding the eukaryotic translation initiation factor $2 \mathrm{~B}[60]$. An increasing amount of evidence suggests that the expression of different pools of tRNAs is important for protein homeostasis under normal and stress conditions [61-63]. One can imagine that POLR3-HLD cases would be more susceptible to certain stressors during CNS development because of Pol III dysfunction, and those would vary among individuals. Since laboratory mice are housed in a relatively stress-free and sterile environment, exposure to environmental stressors during early development might produce a more severe phenotype.

To our knowledge, even the most mildly affected POLR3-HLD patients manifest some aspects of the disease. Thus, the lack of a phenotype in our mutant mice may not solely be explained by the effects of genetic modifiers or environmental stressors. Perhaps a combination of these or other factors discussed herein could account for the normal CNS development of mice carrying the Polr3a c.2015G > A (p.G672E) mutation. This mutation was chosen for this mouse model based on its frequency in the French Canadian patient population and the viability of homozygous carriers $[1,5]$. In light of our results, and considering the genetic and phenotypic heterogeneity in POLR3-HLD, it is possible that other POLR3A, POLR3B or POLR1C mutations may produce a more severe phenotype in mice. Thus, the choice of future mutations for insertion into mice should also 
consider the location of the mutation within important structural elements, such as the bridge helix or the trigger loop, and mutations known to have an impact on Pol III function [22]. Previous studies have found that non-lethal point mutations in conserved regions of yeast Pol III subunits, including two POLR3-HLD-causing mutations, impair Pol III transcription [23, 64-66]. Similar studies on a range of mutations in yeast could aid in selecting mutations to introduce in mice [23]. Alternatively, expression of different mutated forms of Pol III subunits in HeLa cells, as performed with G672E, could also be a helpful tool to choose appropriate mutations. For instance, mutations that cause the accumulation of POLR3A in the cytoplasm may result in a more severe phenotype in mice. However, there is a need for caution since most POLR3-HLD mutations have not been reported in the homozygous state and might be lethal.

Hypomyelination in humans may be due to minor differences in Pol III activity that do not produce the same effect in mice because of a higher tolerance to mutations affecting myelin formation. On the other hand, more severe mutations, such as the ones that are only observed as compound heterozygotes in humans or that cause accumulation of the mutated subunit in the cytoplasm, may be too severe as homozygous alleles and involve other organs or cause developmental failure or embryonic lethality. Nonetheless, both POLR1C mutations that were found to impair complex assembly and nuclear import were present in the homozygous state in patients [3], suggesting that these two features are compatible.

In conclusion, this study illustrates the challenges of developing mouse models for HLD. However, the phenotypic and genetic heterogeneity characteristic of POLR3-HLD patients raises the possibility that introducing other mutations in genes encoding Pol III subunits could lead to a more severe early onset phenotype.

\section{Methods \\ Animals}

All experiments were carried out according to good practice of handling laboratory animals consistent with the Canadian Council on Animal Care and approved by the University Animal Care Committee. Polr $3 a^{K I / K I}$ mice were generated by Ozgene (Bentley, Australia) on a C57BL/6 J genetic background using a conditional mutagenesis strategy modeled after the FLEX switch (see Additional file 1) [67]. To generate whole-body Polr $3 a^{\mathrm{KI} /+}$ mice, Polr $3 a^{\mathrm{FL} /+}$ mice were crossed with transgenic mice expressing $C M V$ Cre (Jackson Laboratory \#006054). Polr3a ${ }^{\mathrm{KI} /+}$ mice were bred together to obtain homozygous Polr $3 a^{\mathrm{KI} / \mathrm{KI}}$ mice (KI/ KI). Full-body Polr $3 a^{+/-}$mice were obtained from the Riken Bioresource Center (\#RBRC03817, strain B6D2F1Polr3a < Gt (LVtrap1)LG04Osb $>$ ), where they were produced by gene trap (Additional file 1: Figure S2). To produce Polr $3 a^{\mathrm{KI} /-}$ mice (KI/KO), we bred KI/KI mice with Polr $3 a^{+/-}$mice. The resulting $\mathrm{KI} / \mathrm{KO}$ mice were bred with $\mathrm{KI} / \mathrm{KI}$ mice to generate litters with the predicted $50 \%$ $\mathrm{KI} / \mathrm{KI}$ and $50 \% \mathrm{KI} / \mathrm{KO}$ mice.

\section{Behavioral tests}

Mice were tested for general locomotion, balance, coordination and strength. We generated a cohort of $15 \mathrm{fe}$ male mice per group (WT, KI/KI, KI/KO), all born within seven days of one another, and submitted them to the following behavioral tests over one year. Phenotyping tests were performed at 40,90 and 270 days of age. The balance beam was also repeated at 365 days of age, while the gait analysis was done at 270 and 365 days old. The balance beam, rotarod and inverted grid tests were performed as previously reported [68, 69]. For the open field test, locomotor activity was assessed over $90 \mathrm{~min}$ in a bank of 8 Versamax Animal Activity Monitor chambers (Accuscan Model RS2USB v4.00, Columbus, OH). Each chamber consisted of a clear acrylic open-field $(40 \mathrm{~cm} \mathrm{~L} \times 40 \mathrm{~cm} \mathrm{~W} \times 30 \mathrm{~cm} \mathrm{H})$, divided into two equal sized chambers $(20 \mathrm{~cm} \mathrm{~L} \times 20 \mathrm{~cm} \mathrm{~W} \times 30 \mathrm{~cm} \mathrm{H})$ by an acrylic partition and was covered by an acrylic lid with air holes. Activity was detected via a grid of infrared photo sensors spaced $2.5 \mathrm{~cm}$ apart and $6 \mathrm{~cm}$ above the floor along the perimeter of the box. All activity chambers were connected to a Versamax data analyzer (Accuscan Model VMX 1.4B, Columbus, OH), which then transmitted data to an HP Compaq Pentium 4 computer for further analysis. Locomotor activity and its distribution within the two chambers were quantified using the Versamax Software System (Version 4.00, Accuscan, Columbus, $\mathrm{OH}$ ). The following measures were recorded for each interval of $10 \mathrm{~min}$ : total distance covered, number of movement bouts, time moving, stereotypy bouts and stereotypy time. For gait analysis, which was performed at 270 and 365 days old only, we used footprint patterns or walking tracks to analyze different parameters [70]. The fore and hind paws of the mice were stained with red and blue washable color paint, respectively and the mice were trained to walk on a paper-covered narrow runway (85 cm long, $6 \mathrm{~cm}$ wide with clear Plexiglas walls) until they reached a dark box at the end of the runway. If the animal stopped in the middle of the track, the test was repeated. The first and last $10 \mathrm{~cm}$ of the footprint were excluded. For analyses, at least four steps from each side per print were measured. Stride length, front and hind limb width and inter limb coordination were measured bilaterally. Upon completion of the last tests, 1-year-old mice were sacrificed and tissues were harvested for histology or for RNA extraction (see below). 


\section{Histology}

For tissue preparation, mice were anesthetized with mouse anesthetic cocktail (ketamine $(100 \mathrm{mg} / \mathrm{ml})$, xylazine $(20 \mathrm{mg} / \mathrm{ml})$ and acepromazine $(10 \mathrm{mg} / \mathrm{ml}))$, perfused transcardially with $0.9 \% \mathrm{NaCl}$ followed by $4 \%$ paraformaldehyde. Brains were dissected and post-fixed for $24 \mathrm{~h}$ at $4{ }^{\circ} \mathrm{C}$ in the same fixative. For Luxol Fast Blue (LFB), tissue processing, embedding, sectioning and staining were performed at the Goodman Cancer Research Centre Histology Facility (McGill University, Montreal, Canada). Briefly, tissues were embedded in paraffin and sectioned on a microtome. Sections of 15 $\mu \mathrm{m}$ were stained with LFB according to standard procedures. Nissl stains and Purkinje cell counts were performed as previously reported [71].

\section{Western Blots}

Cerebellar or cerebral hemispheres were harvested, snap-frozen in liquid nitrogen and homogenized with a Teflon putter in extraction buffer $[10 \mathrm{mM}$ Tris- $\mathrm{HCl}$, pH 7.5, 150 mM NaCl, 1 mM 6 EDTA, 1\% Triton X-100 and protease inhibitors (Roche)] followed by centrifugation at 12,000xg for $30 \mathrm{~min}$ and collection of the supernatant. Protein quantification was determined using DC Protein assay (Bio-Rad). Protein samples were separated onto a 4-12\% NuPAGE Bis Tris gel (ThermoFisher) and transferred onto a nitrocellulose membrane (Bio-Rad). For assessment of myelin protein levels, immunoblots were probed with anti-MBP (Aves Labs Inc. \#MBP), anti-PLP (Abcam \#ab28486), anti-CNPase (Millipore, \#MAB326R), anti-MAG (gift of Dr. David Colman, McGill University) and anti-tubulin (Sigma-Aldrich \#T5168) primary antibodies. For measurement of POLR3A protein levels, immunoblots were probed with anti-POLR3A (Abcam \#ab96328) and anti-actin (Abcam \#ab3280).

\section{RNA extraction and Northern Blots}

Cerebral hemispheres and livers were harvested and snap-frozen in liquid nitrogen. Of note, one-year-old mice were fed ad libitum for their entire life, while 90days-old mice used for Northern Blots were fasted for $16 \mathrm{~h}$ and refed for $5 \mathrm{~h}$ prior to sacrifice and tissue collection in order to stimulate Pol III transcription. Tissues were homogenized in Qiazol lysis reagent (Qiagen). Total RNA was extracted with the miRNeasy kit (Qiagen) and treated with DNAse I (Qiagen) according to the manufacturer's instructions. RNA quality was assessed on an Agilent 2100 Bioanalyzer and RNA Integrity Numbers (RIN) were routinely above 9. For Northern Blots, RNA samples (7.5ug or 10 ug) were separated by denaturing polyacrylamide gel electrophoresis and transferred to Nytran Plus membranes (GE Healthcare). The resulting blots were sequentially hybridized with $\left[{ }^{32} \mathrm{P}\right]$-end labelled probes detecting precursor tRNA ${ }^{\mathrm{Ile}(-}$ TAT), mature tRNA ${ }^{\mathrm{Leu}(\mathrm{AAG})}$ and mature tRNA ${ }^{\mathrm{Glu}(\mathrm{CTC})}$ at $42{ }^{\circ} \mathrm{C} . \mathrm{Bc} 1 \mathrm{RNA}$ levels were subsequently detected with a probe mapping to the $5^{\prime}$ portion of the RNA, as previously described[72]. For n-Tr20, blots were sequentially hybridized with a probe targeting the 3 ' trailer sequence of precursor $\mathrm{n}-\operatorname{Tr} 20$ and a probe targeting both precursor and mature n-Tr20 [37]. All Pol III transcript levels were quantified and normalized to U3 snRNA levels.

\section{Immunofluorescence, affinity purification and mass spectrometry}

HeLa cell lines stably expressing the FLAG-tagged POLR3A subunit (WT or G672E-mutated) were generated by transfection with Lipofectamine according to the manufacturer's instructions (ThermoFisher). Immunofluorescence was performed using an anti-FLAG antibody, as previously described [3]. For affinity purification, cytoplasm and nuclei were prepared as reported before [73]. Briefly, cells were lysed by mechanical homogenization in lysis buffer $[10 \mathrm{mM}$ Tris- $\mathrm{HCl}$ ( $\mathrm{pH}$ 8), 0.34 $\mathrm{M}$ sucrose, $3 \mathrm{mM} \mathrm{CaCl} 2,2 \mathrm{mM} \mathrm{MgOAc}$, $0.1 \mathrm{mM}$ EDTA, $1 \mathrm{mM}$ DTT, $0.5 \%$ Nonidet P-40 and protease inhibitors]. Whole cell extracts were centrifuged at $3,500 \times \mathrm{g}$ for $15 \mathrm{~min}$ and the supernatant, which represents the cytoplasmic fraction, was saved. The pellet containing the nuclei was resuspended, lysed by mechanical homogenization in lysis buffer [20 mM HEPES (pH 7.9), $1.5 \mathrm{mM} \mathrm{MgCl} 2,150 \mathrm{mM}$ KOAc, 3 mM EDTA, $10 \%$ glycerol, $1 \mathrm{mM}$ DTT, $0.1 \%$ Nonidet P-40 and protease inhibitors] and, centrifuged at $15,000 \times \mathrm{g}$ for $30 \mathrm{~min}$. The supernatant, which corresponds to the nucleoplasmic fraction, was saved. Cytoplasm and nuclei were mixed; fractions were centrifuged at $124,000 \times \mathrm{g}$ and dialyzed overnight in dialysis buffer $[10 \mathrm{mM}$ Hepes (pH 7.9), 0.1 mM EDTA (pH 8), $0.1 \mathrm{mM}$ DTT, $0.1 \mathrm{M}$ KOAc and $10 \%$ glycerol]. The following day, the fractions were clarified by centrifugation at $20,000 \times \mathrm{g}$ for $30 \mathrm{~min}$, and the supernatants containing the solubilized proteins were collected. Anti-FLAG affinity purification and mass spectrometry were performed as previously reported [3]. Data analysis is described in Additional file 1: Supplementary Methods.

\section{ChIP-qPCR}

For ChIP-qPCR, FLAG-tagged POLR3A variants (WT or G672E) were transiently transfected in HEK293 cells for $24 \mathrm{~h}$ with Lipofectamine. Transfections were performed in triplicate. Cells were crosslinked with $1 \%$ formaldehyde directly in the cell medium for 5 min followed by quenching for $5 \mathrm{~min}$ in $125 \mathrm{mM}$ glycine. ChIP was performed as reported previously [3]. For qPCR, $10 \mathrm{ng}$ of chromatin were used to amplify two Pol III target genes (VTRNA1-1 and tRNA-iMet) and a control locus on 
chromosome 13 that is not bound by Pol III. The following primers were used: VTRNA1-1: 5'-GGC TGG CTT TAG CTC AGC G-3' and 5' - TCT CGA ACA ACC CAG ACA GGT-3', tRNA-iMet: 5' -AGA GTG GCG CAG CGG AA3 ' and 5'- TAG CAG AGG ATG GTT TCG ATC C-3', unbound locus: 5'-GGC ACT GTC TTG TCA CTG CAC ATT-3' and 5' - TGG AAA CAG CCA TTG AGA ACA CC-3'.

\section{Statistical analyses}

Data are presented as mean +/- SEM. Preliminary analysis revealed significant differences in weight among the genotypes, particularly at the later ages (see Additional file 1: Figure S3). As weight can significantly impact motor performance, behavioral measures at each age were examined by one-way analysis of covariance (ANCOVA) with weight as the covariate. Behavioral measures are reported as ANCOVA (weight) adjusted least squares means $+/-$ SEMs in Fig. 1. Unadjusted means +/- SEMs are shown in Figure S4 (see Additional file 1). Purkinje cell counts and RNA quantifications were compared using one-way ANOVA. ANOVAs were performed with GraphPad Prism and ANCOVAs with JMP (Version 13). In all cases, the threshold for statistical significance was set at $p$-value $<0.05$.

\section{Additional file}

Additional file 1: Figures S1. to S6, Table S1. and Supplementary Methods (PDF $7816 \mathrm{~kb}$ )

\section{Abbreviations}

cDNA: Complementary DNA; CNS: Central nervous system;

HLD: Hypomyelinating leukodystrophy; Kl: Knock-in; KO: Knock-out; LFB: Luxol Fast Blue; MRI: Magnetic resonance imaging: MS: Mass spectrometry; ChIP: Chromatin immunoprecipitation; ncRNA: Non-coding RNA; Pol III: RNA Polymerase III; rRNA: Ribosomal RNA; SEM: Standard error of the mean; tRNA: transfer RNA; WT: Wild-type

\section{Acknowledgements}

We are grateful to Dr. Roberta La Piana for critical reading of the manuscript and insightful comments. We would like to thank Eve-Marie Charbonneau and Geneviève Hamel from the Douglas Neurophenotyping Platform for their help with mouse colony management and behavioral assays, as well as the Goodman Cancer Research Centre Histology Facility for performing LFB stains and the McGill University and Génome Québec Innovation Center for Sanger sequencing.

\section{Funding}

This project was supported by grants from the Fondation Leuco Dystrophie, the European Leukodystrophy Association and the Canadian Institutes of Health Research (CIHR) (MOP \#126141). KC receives a Doctoral Award from the Fonds de recherche du Québec - Santé (FRQS). GB has received a Research Scholar Junior 1 (2012-2016) salary award from the FRQS and the New Investigator salary award (2017-2022) from the CIHR (MOP-G-287547). MT was supported by grants from the INSERM and the Ligue Nationale contre le Cancer (Equipe labellisée). CLK receives salary awards from the FRQS.

\section{Availability of data and materials}

The datasets used and/or analysed during the current study are available from the corresponding author on reasonable request.

\section{Authors' contributions}

KC and BB conceived the study. KC, RDM, RL, BC, IMW, CLK and BB designed the experiments. KC managed and analyzed behavioral experiments. SY, MJD, NS, RL, FN and KC collected and processed tissues, performed genotyping, RT-PCR and PCR for Sanger sequencing. KC, SY, RL and FN performed and analyzed histology and Western Blots. RDM and IMW conducted and analyzed Northern Blot experiments. DF and AB performed and analyzed immunofluorescence, affinity purification and ChIP-qPCR experiments. CP analyzed mass spectrometry data. JR participated in the statistical analysis of behavioral experiments. TEK, GB and MT provided advice regarding experimental design and data analysis and contributed to interpretation of results. KC, CLK and BB wrote the manuscript. All authors read and approved the final manuscript.

\section{Competing interests}

The authors declare that they have no competing interests.

\section{Consent for publication}

Not applicable

\section{Ethics approval}

All experiments were performed according to good practice of handling laboratory animals consistent with the Canadian Council on Animal Care and approved by the McGill University Animal Care Committee.

\section{Publisher's Note}

Springer Nature remains neutral with regard to jurisdictional claims in published maps and institutional affiliations.

\section{Author details}

${ }^{1}$ Montreal Neurological Institute, McGill University, 3801 University Street, room 622, Montréal, Québec H3A 2B4, Canada. ²Department of Human Genetics, McGill University, Montréal, Québec, Canada. ${ }^{3}$ Lady Davis Institute for Medical Research, Jewish General Hospital, Montréal, Québec, Canada. ${ }^{4}$ Department of Biochemistry, Albert Einstein College of Medicine, Bronx, New York, USA. ${ }^{5}$ Translational Proteomics Laboratory, Institut de recherches cliniques de Montréal (IRCM), Montréal, Québec, Canada. ${ }^{6}$ Douglas Institute Research Center, Montréal, Québec, Canada. ${ }^{7}$ Departments of Neurology and Neurosurgery, and Pediatrics, McGill University, Montreal, Canada. ${ }^{8}$ Department of Medical Genetics, Montreal Children's Hospital, McGill University Health Center, Montreal, Canada. ${ }^{9}$ Child Health and Human Development Program, Research Institute of the McGill University Health Center, Montreal, Canada. ${ }^{10}$ INSERM U1212 - CNRS UMR5320, Université de Bordeaux, Bordeaux, France. ${ }^{11}$ Département de biochimie et médecine moléculaire, Université de Montréal, Montréal, Québec, Canada.

Received: 3 January 2017 Accepted: 4 April 2017

Published online: 13 April 2017

\section{References}

1. Bernard G, Chouery E, Putorti ML, Tetreault M, Takanohashi A, Carosso G, Clement I, Boespflug-Tanguy O, Rodriguez D, Delague V, et al. Mutations of POLR3A encoding a catalytic subunit of RNA polymerase Pol III cause a recessive hypomyelinating leukodystrophy. Am J Hum Genet. 2011:89:415-23.

2. Tetreault M, Choquet $K$, Orcesi $S$, Tonduti D, Balottin U, Teichmann M Fribourg S, Schiffmann R, Brais B, Vanderver A, Bernard G. Recessive mutations in POLR3B, encoding the second largest subunit of Pol III, cause a rare hypomyelinating leukodystrophy. Am J Hum Genet. 2011;89:652-5.

3. Thiffault I, Wolf NI, Forget D, Guerrero K, Tran LT, Choquet K, Lavallee-Adam M, Poitras C, Brais B, Yoon G, et al. Recessive mutations in POLR1C cause a leukodystrophy by impairing biogenesis of RNA polymerase III. Nat Commun. 2015;6:7623

4. Saitsu H, Osaka H, Sasaki M, Takanashi J, Hamada K, Yamashita A, Shibayama $\mathrm{H}$, Shiina $\mathrm{M}$, Kondo $\mathrm{Y}$, Nishiyama $\mathrm{K}$, et al. Mutations in POLR3A and POLR3B encoding RNA Polymerase III subunits cause an autosomal-recessive hypomyelinating leukoencephalopathy. Am J Hum Genet. 2011;89:644-51.

5. Wolf NI, Vanderver A, van Spaendonk RM, Schiffmann R, Brais B, Bugiani M Sistermans E, Catsman-Berrevoets C, Kros JM, Pinto PS, et al. Clinical spectrum of 4H leukodystrophy caused by POLR3A and POLR3B mutations. Neurology. 2014; 83:1898-905. 
6. La Piana R, Tonduti D, Gordish Dressman H, Schmidt JL, Murnick J, Brais B, Bernard G, Vanderver A. Brain magnetic resonance imaging (MRI) pattern recognition in Pol III-related leukodystrophies. J Child Neurol. 2014;29:214-20.

7. Steenweg ME, Vanderver A, Blaser S, Bizzi A, de Koning TJ, Mancini GM, van Wieringen WN, Barkhof F, Wolf NI, van der Knaap MS. Magnetic resonance imaging pattern recognition in hypomyelinating disorders. Brain. 2010;133:2971-82.

8. La Piana R, Cayami FK, Tran LT, Guerrero K, van Spaendonk R, Ounap K, Pajusalu S, Haack T, Wassmer E, Timmann D, et al. Diffuse hypomyelination is not obligate for POLR3-related disorders. Neurology. 2016;86:1622-6.

9. Dieci G, Fiorino G, Castelnuovo M, Teichmann M, Pagano A. The expanding RNA polymerase III transcriptome. Trends Genet. 2007;23:614-22.

10. Cayami FK, La Piana R, van Spaendonk RM, Nickel M, Bley A, Guerrero K, Tran LT, van der Knaap MS, Bernard G, Wolf NI. POLR3A and POLR3B Mutations in Unclassified Hypomyelination. Neuropediatrics. 2015;46:221-8.

11. Daoud H, Tetreault M, Gibson W, Guerrero K, Cohen A, Gburek-Augustat J, Synofzik M, Brais B, Stevens CA, Sanchez-Carpintero R, et al. Mutations in POLR3A and POLR3B are a major cause of hypomyelinating leukodystrophies with or without dental abnormalities and/or hypogonadotropic hypogonadism. J Med Genet. 2013;50:194-7.

12. Gutierrez M, Thiffault I, Guerrero K, Martos-Moreno GA, Tran LT, Benko W, van der Knaap MS, van Spaendonk RM, Wolf NI, Bernard G. Large exonic deletions in POLR3B gene cause POLR3-related leukodystrophy. Orphanet J Rare Dis. 2015;10:69.

13. Potic A, Brais B, Choquet K, Schiffmann R, Bernard G. 4H syndrome with late-onset growth hormone deficiency caused by POLR3A mutations. Arch Neurol. 2012;69:920-3.

14. Shimojima K, Shimada S, Tamasaki A, Akaboshi S, Komoike Y, Saito A, Furukawa T, Yamamoto T. Novel compound heterozygous mutations of POLR3A revealed by whole-exome sequencing in a patient with hypomyelination. Brain Dev. 2014;36:315-21.

15. Terao Y, Saitsu H, Segawa M, Kondo Y, Sakamoto K, Matsumoto N, Tsuji S, Nomura $Y$. Diffuse central hypomyelination presenting as $4 \mathrm{H}$ syndrome caused by compound heterozygous mutations in POLR3A encoding the catalytic subunit of polymerase III. J Neurol Sci. 2012;320:102-5.

16. Battini R, Bertelloni S, Astrea G, Casarano M, Travaglini L, Baroncelli G, Pasquariello R, Bertini E, Cioni G. Longitudinal follow up of a boy affected by Pol III-related leukodystrophy: a detailed phenotype description. BMC Med Genet. 2015;16:53.

17. Jurkiewicz E, Dunin-Wasowicz D, Gieruszczak-Bialek D, Malczyk K, Guerrero K, Gutierrez M, Tran L, Bernard G. Recessive Mutations in POLR3B Encoding RNA Polymerase III Subunit Causing Diffuse Hypomyelination in Patients with $4 \mathrm{H}$ Leukodystrophy with Polymicrogyria and Cataracts. Clin Neuroradiol. 2015. [Epub ahead of print]

18. Billington E, Bernard G, Gibson W, Corenblum B. Endocrine Aspects of $4 \mathrm{H}$ Leukodystrophy: A Case Report and Review of the Literature. Case Rep Endocrinol. 2015;2015:314594

19. Synofzik M, Bernard G, Lindig T, Gburek-Augustat J. Teaching neuroimages: hypomyelinating leukodystrophy with hypodontia due to POLR3B: look into a leukodystrophy's mouth. Neurology. 2013;81:e145.

20. Richards MR, Plummer L, Chan YM, Lippincott MF, Quinton R, Kumanov P, Seminara SB. Phenotypic spectrum of POLR3B mutations: isolated hypogonadotropic hypogonadism without neurological or dental anomalies. J Med Genet. 2016;54:19-25.

21. Azmanov DN, Siira SJ, Chamova T, Kaprelyan A, Guergueltcheva V, Shearwood AJ, Liu G, Morar B, Rackham O, Bynevelt M, et al. Transcriptomewide effects of a POLR3A gene mutation in patients with an unusual phenotype of striatal involvement. Hum Mol Genet. 2016;25:4302-14.

22. Arimbasseri AG, Maraia RJ. RNA Polymerase III Advances: Structural and tRNA Functional Views. Trends Biochem Sci. 2016;41:546-59.

23. Arimbasseri AG, Blewett NH, Iben JR, Lamichhane TN, Cherkasova V, Hafner M, Maraia RJ. RNA Polymerase III Output Is Functionally Linked to tRNA Dimethyl-G26 Modification. PLoS Genet. 2015;11:e1005671.

24. Dittmar KA, Goodenbour JM, Pan T. Tissue-specific differences in human transfer RNA expression. PLoS Genet. 2006;2:e221.

25. Castle JC, Armour CD, Lower M, Haynor D, Biery M, Bouzek H, Chen R, Jackson S, Johnson JM, Rohl CA, Raymond CK. Digital genome-wide ncRNA expression, including SnoRNAs, across 11 human tissues using polyA-neutral amplification. PLoS One. 2010;5:e11779.

26. Karaca E, Weitzer S, Pehlivan D, Shiraishi H, Gogakos T, Hanada T, Jhangian SN, Wiszniewski W, Withers M, Campbell IM, et al. Human CLP1 mutations alter tRNA biogenesis, affecting both peripheral and central nervous system function. Cell. 2014;157:636-50.
27. Schaffer AE, Eggens VR, Caglayan AO, Reuter MS, Scott E, Coufal NG, Silhavy $J$, Xue $Y$, Kayserili H, Yasuno K, et al. CLP1 founder mutation links tRNA splicing and maturation to cerebellar development and neurodegeneration. Cell. 2014;157:651-63.

28. Borck G, Hog F, Dentici ML, Tan PL, Sowada N, Medeira A, Gueneau L, Thiele $\mathrm{H}$, Kousi $\mathrm{M}$, Lepri $\mathrm{F}$, et al. BRF1 mutations alter RNA polymerase IIIdependent transcription and cause neurodevelopmental anomalies. Genome Res. 2015;25:155-66.

29. Blanco S, Dietmann S, Flores JV, Hussain S, Kutter C, Humphreys P, Lukk M, Lombard $P$, Treps $L$, Popis $M$, et al. Aberrant methylation of tRNAs links cellular stress to neuro-developmental disorders. EMBO J. 2014;33:2020-39.

30. Taft RJ, Vanderver A, Leventer RJ, Damiani SA, Simons C, Grimmond SM, Miller D, Schmidt J, Lockhart PJ, Pope $\mathrm{K}$, et al. Mutations in DARS cause hypomyelination with brain stem and spinal cord involvement and leg spasticity. Am J Hum Genet. 2013;92:774-80.

31. Feinstein M, Markus B, Noyman I, Shalev H, Flusser H, Shelef I, LianiLeibson K, Shorer Z, Cohen I, Khateeb S, et al. Pelizaeus-Merzbacher-like disease caused by AIMP1/p43 homozygous mutation. Am J Hum Genet. 2010;87:820-8.

32. Wolf NI, Salomons GS, Rodenburg RJ, Pouwels PJ, Schieving JH, Derks TG, Fock JM, Rump P, van Beek DM, van der Knaap MS, Waisfisz Q. Mutations in RARS cause hypomyelination. Ann Neurol. 2014;76:134-9.

33. Vanderver A, Tonduti D, Bernard G, Lai J, Rossi C, Carosso G, Quezado M, Wong K, Schiffmann R. More than hypomyelination in Pol-III disorder. J Neuropathol Exp Neurol. 2013;72:67-75.

34. Upadhya R, Lee J, Willis IM. Maf1 is an essential mediator of diverse signals that repress RNA polymerase III transcription. Mol Cell. 2002;10:1489-94.

35. Bonhoure N, Byrnes A, Moir RD, Hodroj W, Preitner F, Praz V, Marcelin G, Chua Jr SC, Martinez-Lopez N, Singh R, et al. Loss of the RNA polymerase III repressor MAF1 confers obesity resistance. Genes Dev. 2015;29:934-47.

36. Michels AA, Robitaille AM, Buczynski-Ruchonnet D, Hodroj W, Reina JH, Hall MN, Hernandez N. mTORC1 directly phosphorylates and regulates human MAF1. Mol Cell Biol. 2010;30:3749-57.

37. Ishimura R, Nagy G, Dotu I, Zhou H, Yang XL, Schimmel P, Senju S, Nishimura Y, Chuang JH, Ackerman SL. RNA function. Ribosome stalling induced by mutation of a CNS-specific tRNA causes neurodegeneration. Science. 2014;345:455-9.

38. Yee NS, Gong W, Huang Y, Lorent K, Dolan AC, Maraia RJ, Pack M. Mutation of RNA Pol III subunit rpc2/polr3b Leads to Deficiency of Subunit Rpc11 and disrupts zebrafish digestive development. PLoS Biol. 2007;5:e312.

39. White RJ. Transcription by RNA polymerase III: more complex than we thought. Nat Rev Genet. 2011:12:459-63.

40. Sievers F, Wilm A, Dineen D, Gibson TJ, Karplus K, Li W, Lopez R, McWilliam H, Remmert M, Soding J, et al. Fast, scalable generation of high-quality protein multiple sequence alignments using Clustal Omega. Mol Syst Biol. 2011;7:539.

41. Ornelas IM, McLane LE, Saliu A, Evangelou AV, Khandker L, Wood TL. Heterogeneity in oligodendroglia: Is it relevant to mouse models and human disease? J Neurosci Res. 2016;94:1421-33.

42. Fields RD. White matter matters. Sci Am. 2008:298:42-9.

43. Tress O, Maglione M, Zlomuzica A, May D, Dicke N, Degen J, Dere E, Kettenmann H, Hartmann D, Willecke K. Pathologic and phenotypic alterations in a mouse expressing a connexin47 missense mutation that causes PelizaeusMerzbacher-like disease in humans. PLoS Genet. 2011;7:e1002146.

44. Jakovcevski I, Filipovic R, Mo Z, Rakic S, Zecevic N. Oligodendrocyte development and the onset of myelination in the human fetal brain. Front Neuroanat. 2009;3:5

45. Odermatt B, Wellershaus K, Wallraff A, Seifert G, Degen J, Euwens C, Fuss B, Bussow H, Schilling K, Steinhauser C, Willecke K. Connexin 47 (Cx47)deficient mice with enhanced green fluorescent protein reporter gene reveal predominant oligodendrocytic expression of Cx47 and display vacuolized myelin in the CNS. J Neurosci. 2003;23:4549-59.

46. Pujol A, Hindelang C, Callizot N, Bartsch U, Schachner M, Mandel JL. Late onset neurological phenotype of the X-ALD gene inactivation in mice: a mouse model for adrenomyeloneuropathy. Hum Mol Genet. 2002;11:499-505.

47. Duning K, Buck F, Barnekow A, Kremerskothen J. SYNCRIP, a component of dendritically localized mRNPs, binds to the translation regulator BC200 RNA. J Neurochem. 2008;105:351-9.

48. Tiedge $H$, Chen W, Brosius J. Primary structure, neural-specific expression, and dendritic location of human BC200 RNA. J Neurosci. 1993;13:2382-90.

49. Massone S, Vassallo I, Castelnuovo M, Fiorino G, Gatta E, Robello M, Borgh R, Tabaton M, Russo C, Dieci G, et al. RNA polymerase III drives alternative 
splicing of the potassium channel-interacting protein contributing to brain complexity and neurodegeneration. J Cell Biol. 2011;193:851-66.

50. Massone S, Vassallo I, Fiorino G, Castelnuovo M, Barbieri F, Borghi R, Tabaton M, Robello M, Gatta E, Russo C, et al. 17A, a novel non-coding RNA, regulates GABA B alternative splicing and signaling in response to inflammatory stimuli and in Alzheimer disease. Neurobiol Dis. 2011:41:308-17.

51. Castelnuovo M, Massone S, Tasso R, Fiorino G, Gatti M, Robello M, Gatta E, Berger A, Strub K, Florio T, et al. An Alu-like RNA promotes cell differentiation and reduces malignancy of human neuroblastoma cells. FASEB J. 2010;24:4033-46.

52. Gigoni A, Costa D, Gaetani M, Tasso R, Villa F, Florio T, Pagano A. Downregulation of $21 \mathrm{~A}$ Alu RNA as a tool to boost proliferation maintaining the tissue regeneration potential of progenitor cells. Cell Cycle. 2016;15:2420-30.

53. Penna I, Vassallo I, Nizzari M, Russo D, Costa D, Menichini P, Poggi A, Russo C, Dieci G, Florio T, et al. A novel snRNA-like transcript affects amyloidogenesis and cell cycle progression through perturbation of Fe65L1 (APBB2) alternative splicing. Biochim Biophys Acta. 1833;2013:1511-26.

54. Pagano A, Castelnuovo M, Tortelli F, Ferrari R, Dieci G, Cancedda R. New small nuclear RNA gene-like transcriptional units as sources of regulatory transcripts. PLoS Genet. 2007;3:e1.

55. Mack JT, Beljanski V, Soulika AM, Townsend DM, Brown CB, Davis W, Tew KD. "Skittish" Abca2 knockout mice display tremor, hyperactivity, and abnormal myelin ultrastructure in the central nervous system. Mol Cell Biol. 2007;27:44-53.

56. De Munter S, Verheijden S, Vanderstuyft E, Malheiro AR, Brites P, Gall D, Schiffmann SN, Baes M. Early-onset Purkinje cell dysfunction underlies cerebellar ataxia in peroxisomal multifunctional protein-2 deficiency. Neurobiol Dis. 2016;94:157-68.

57. Coley WD, Bogdanik L, Vila MC, Yu Q, Van Der Meulen JH, Rayavarapu S, Novak JS, Nearing M, Quinn JL, Saunders A, et al. Effect of genetic background on the dystrophic phenotype in mdx mice. Hum Mol Genet. 2016:25:130-45.

58. Hatzipetros T, Bogdanik LP, Tassinari VR, Kidd JD, Moreno AJ, Davis C, Osborne M, Austin A, Vieira FG, Lutz C, Perrin S. C57BL/6 I congenic Prp-TDP43A315T mice develop progressive neurodegeneration in the myenteric plexus of the colon without exhibiting key features of ALS. Brain Res. 2014;1584:59-72.

59. Frankel WN, Mahaffey CL, McGarr TC, Beyer BJ, Letts VA. Unraveling genetic modifiers in the gria4 mouse model of absence epilepsy. PLoS Genet. 2014;10: e1004454.

60. van der Knaap MS, Pronk JC, Scheper GC. Vanishing white matter disease. Lancet Neurol. 2006;5:413-23.

61. Orioli A, Praz V, Lhote P, Hernandez N. Human MAF1 targets and represses active RNA polymerase III genes by preventing recruitment rather than inducing long-term transcriptional arrest. Genome Res. 2016;26:624-35.

62. Gingold H, Tehler D, Christoffersen NR, Nielsen MM, Asmar F, Kooistra SM, Christophersen NS, Christensen LL, Borre M, Sorensen KD, et al. A dual program for translation regulation in cellular proliferation and differentiation. Cell. 2014;158:1281-92.

63. Orioli A. tRNA biology in the omics era: Stress signalling dynamics and cancer progression. Bioessays. 2017;39 [epub 2016 Dec 27]

64. Dieci G, Hermann-Le Denmat S, Lukhtanov E, Thuriaux P, Werner M, Sentenac A. A universally conserved region of the largest subunit participates in the active site of RNA polymerase III. EMBO J. 1995;14:3766-76.

65. Thuillier V, Brun I, Sentenac A, Werner M. Mutations in the alpha-amanitin conserved domain of the largest subunit of yeast RNA polymerase III affect pausing, RNA cleavage and transcriptional transitions. EMBO J. 1996;15:618-29.

66. Brun I, Sentenac A, Werner M. Dual role of the C34 subunit of RNA polymerase III in transcription initiation. EMBO J. 1997;16:5730-41.

67. Schnutgen F, Ghyselinck NB. Adopting the good reFLEXes when generating conditional alterations in the mouse genome. Transgenic Res. 2007;16:405-13.

68. Luong TN, Carlisle HJ, Southwell A, Patterson PH. Assessment of motor balance and coordination in mice using the balance beam. J Vis Exp. 2011;(49).

69. Lariviere R, Gaudet R, Gentil BJ, Girard M, Conte TC, Minotti S, LeclercDesaulniers K, Gehring K, McKinney RA, Shoubridge EA, et al. Sacs knockout mice present pathophysiological defects underlying autosomal recessive spastic ataxia of Charlevoix-Saguenay. Hum Mol Genet. 2015;24:727-39.

70. Carter RJ, Morton J, Dunnett SB. Motor coordination and balance in rodents. Curr Protoc Neurosci. 2001;Chapter 8:Unit 8-12.

71. Girard M, Lariviere R, Parfitt DA, Deane EC, Gaudet R, Nossova N, Blondeau F, Prenosil G, Vermeulen EG, Duchen MR, et al. Mitochondrial dysfunction and Purkinje cell loss in autosomal recessive spastic ataxia of CharlevoixSaguenay (ARSACS). Proc Natl Acad Sci U S A. 2012;109:1661-6.

72. Skryabin BV, Sukonina V, Jordan U, Lewejohann L, Sachser N, Muslimov I, Tiedge H, Brosius J. Neuronal untranslated BC1 RNA: targeted gene elimination in mice. Mol Cell Biol. 2003;23:6435-41.

73. Lavallee-Adam M, Rousseau J, Domecq C, Bouchard A, Forget D, Faubert D, Blanchette M, Coulombe B. Discovery of cell compartment specific proteinprotein interactions using affinity purification combined with tandem mass spectrometry. J Proteome Res. 2013;12:272-81.

\section{Submit your next manuscript to BioMed Central and we will help you at every step:}

- We accept pre-submission inquiries

- Our selector tool helps you to find the most relevant journal

- We provide round the clock customer support

- Convenient online submission

- Thorough peer review

- Inclusion in PubMed and all major indexing services

- Maximum visibility for your research

Submit your manuscript at www.biomedcentral.com/submit
(O) BioMed Central 